\title{
A Study on Online Delivery of Digital Textbooks in Korea
}

\author{
Pyung Kim*, Jeong-Su Yu \\ Department of Computer Education, Jeonju National University of Education, Korea
}

Copyright $\odot 2019$ by authors, all rights reserved. Authors agree that this article remains permanently open access under the terms of the Creative Commons Attribution License 4.0 International License

\begin{abstract}
Rapid ICT development is changing the whole educational landscape, including learning content, teaching and learning methods, and the role of the teacher and the student. Digital textbooks help the teacher and the student interact with each other and provide unlimited access to learning content and services. Various studies demonstrate the efficiency and usefulness of digital textbooks. As current plans foresee the development of digital textbooks until 2020, there is a need for their effective online distribution. This requires analyzing the range of digital textbooks, their content and functionality, assessing the number of users, including students and teachers, and evaluating the state of the schools' wireless infrastructure and the means of online delivery. In this study we suggest a reliable and efficient online infrastructure for delivering voluminous digital textbooks that provides better availability and usability of e-learning services.
\end{abstract}

Keywords Digital Textbooks, Online Delivery, Content Delivery Service, Distribution Method

\section{Introduction}

Rapid social changes towards the digital World quickly accelerate the convergence between Information and Communication Technology and the education sector. ICT progress changes educational content, teaching and learning methods, learning environment, roles of schools and teachers, as well as the very demand for education and the way people learn [1]. Digital textbooks extend the benefits of traditional printed matter with rich combination of multimedia, video, animation, virtual reality and linking additional information offering much faster and accurate delivery of the relevant content. In addition, digital matter allows access to real-time data stored in the databases, which is virtually impossible with traditional textbooks. Digital devices further make it possible effective content delivery without limitations in time and place and convenient combination of educational materials across school grades and curricula.

Various studies [2]-[4] demonstrate the efficiency and usefulness of digital textbooks. Digital content delivered over SNS and other media offers many opportunities for teachers and students and greatly enhances the learning process through interaction and immediate feedback. Extensive additional content and interactivity make it possible to hold student-focused classes and facilitate self-paced learning. During a class the teacher can use digital textbooks to offer a variety of additional resources and interactive features that increases students' interest and understanding of the educational content. In turn, students get more opportunities to learn as they can always access educational content and services when needed.

In Korea, commercial introduction of digital textbooks has started in March 2007 with publication of the "Digital Textbook Commercialization Plan". In 2008, a digital textbook viewer was developed. By 2011, digital textbooks for 5-6 grade elementary schools (Korean language, Social Science, Natural Science, Mathematics, Music, and English Language) and $1^{\text {st }}$ grade middle school (English Language) have been developed under the pilot program. In 2012, the topic coverage was extended, and since 2014 a program for total 163 digital textbooks (81 elementary schools, and 82 middle schools) was launched. In 2018, the development of digital textbooks for 3-4 grade elementary school and 1 grade middle school (Social Science and English Language) was launched for the period up to 2020. However, to successfully introduce digital textbooks into the school environment, in addition to product quality and usability features, we further need a reliable delivery service.

In this study, we examine the features of digital textbooks and suggest an efficient method of online delivery. To this end, we suggest factors that affect usability and accessibility of digital textbooks, such as usage scenarios, school infrastructure, the number of 
students, and delivery methods.

In Chapter 2, we briefly refer to the related works on digital textbook and reviews the characteristics of digital textbooks and Content Delivery Network (CDN). Chapter 3 addresses current situation in online delivery of curriculum books. In Chapter 4 we consider online delivery methods and the related infrastructure. Chapter 5 presents research conclusions and discusses future research.

\section{Related Works}

In order to suggest efficient methods of online delivery of digital textbooks, it is necessary to understand their content, functionality and effectiveness, as well as how CDN services work.

\subsection{Content, Features and Effectiveness of Digital Textbooks}

As the paradigm shifts to the world of 21st century learning, the roles of teachers, students, and families are changing. Therefore, studies on digital textbooks are one of the ways to provide equal educational opportunities and convenient educational contents [1-4].

Jang [1] reviewed diverse contents development methods for digital textbooks, service provision, and proposed the most appropriate model suitable for digital textbooks in cloud computing environment. Cloud Computing enables users to use mobile digital textbooks anytime and anywhere to learn from a variety of materials depending on their learning ability and intellectual level. Joo [2-16] investigated students' perspectives to use new digital media and new services in an educational context. In this study, satisfaction with the expectation of digital textbooks increases the perception of enjoyment and usability, and enjoyment and perceived usefulness indirectly affect the persistence intention of using digital textbooks. Perceived usefulness and satisfaction positively affected continuance intention towards digital textbooks. Kim [3] proposed an XML - based digital textbook that maximizes the learning effect by integrating the advantages of traditional digital textbooks with digital media functions. XML document format is established to facilitate more flexible use of and the interoperability of digital textbooks among different users and providers. This study demonstrated that digital textbooks provide diverse learning opportunities and improve learning outcomes through an experiment for two semesters at three elementary schools. Lee [4-17] suggested innovative approaches for u-Learning environment in public education with digital textbook. In this study, they surveyed the status of u-learning environment in Korea, examined the satisfaction of digital textbooks, and confirmed the satisfaction of digital textbooks through questionnaires on learning outcomes. It also provided educators with useful guidelines for improving the u-learning environment.

\subsection{CDN Service}

A CDN is a platform of distributed servers optimized for content delivery, including Web applications and streaming media, where the servers can be distributed across numerous physical locations and networks [5-7-19].

Fast and secure content delivery is achieved through the direct response to client content requests with a distributed network. As a matter of fact, a CDN acts as a mediator between content servers where the content is stored and the clients. Without CDN, content servers should have responded to every user request directly, resulting in massive traffic to the content server, increased load, and the likelihood of failure. With CDN, user requests are routed to the last-used CDN server. If the server already has a cached version of the requested data, it simply returns it to the user. If no cached data is found locally, the server requests other $\mathrm{CDN}$ servers. If the requested data is found, it is sent to the user. If the requested content is not available or obsolete, the CDN acts as a request proxy to the content server. When the file is received, it is sent to the user and stored with CDN to serve future requests. CDNs are mostly used to deliver websites but can also serve other types of content, such as $4 \mathrm{~K}$ and $\mathrm{HD}$ videos, audio streams, software updates for applications, game, and OS, large data records, such as medical or financial data.

Figure 1 shows the advantages of CDN compared to before and after use of CDN service [8-18]. The advantages and disadvantages of CDN service are as follows. The following are the advantages of the CDN service,

- Improve Speeds: A CDN is a local server that handles all traffic and requests on the source server by providing an effectively generated local version of the content that end users can access. This allows the user to improve the speed of website immediately.

- $\quad$ Stronger Security: Implementing the CDN provides the source server with effective protection from malicious software or DDoS attacks.

- Built-In Analytics: The statist2ics provided by the $\mathrm{CDN}$ include bandwidth usage, cache and non-cache hit ratio, and content area analysis.

- Minimize Crashes: With CDNs, traffic can be distributed and balanced across networks and regions, so requests are not overloaded on the source server.

Save Cost: With CDN services, infrastructure construction and management costs can be reduced and content providers can flexibly cope with the increase and decrease of users and traffic. 


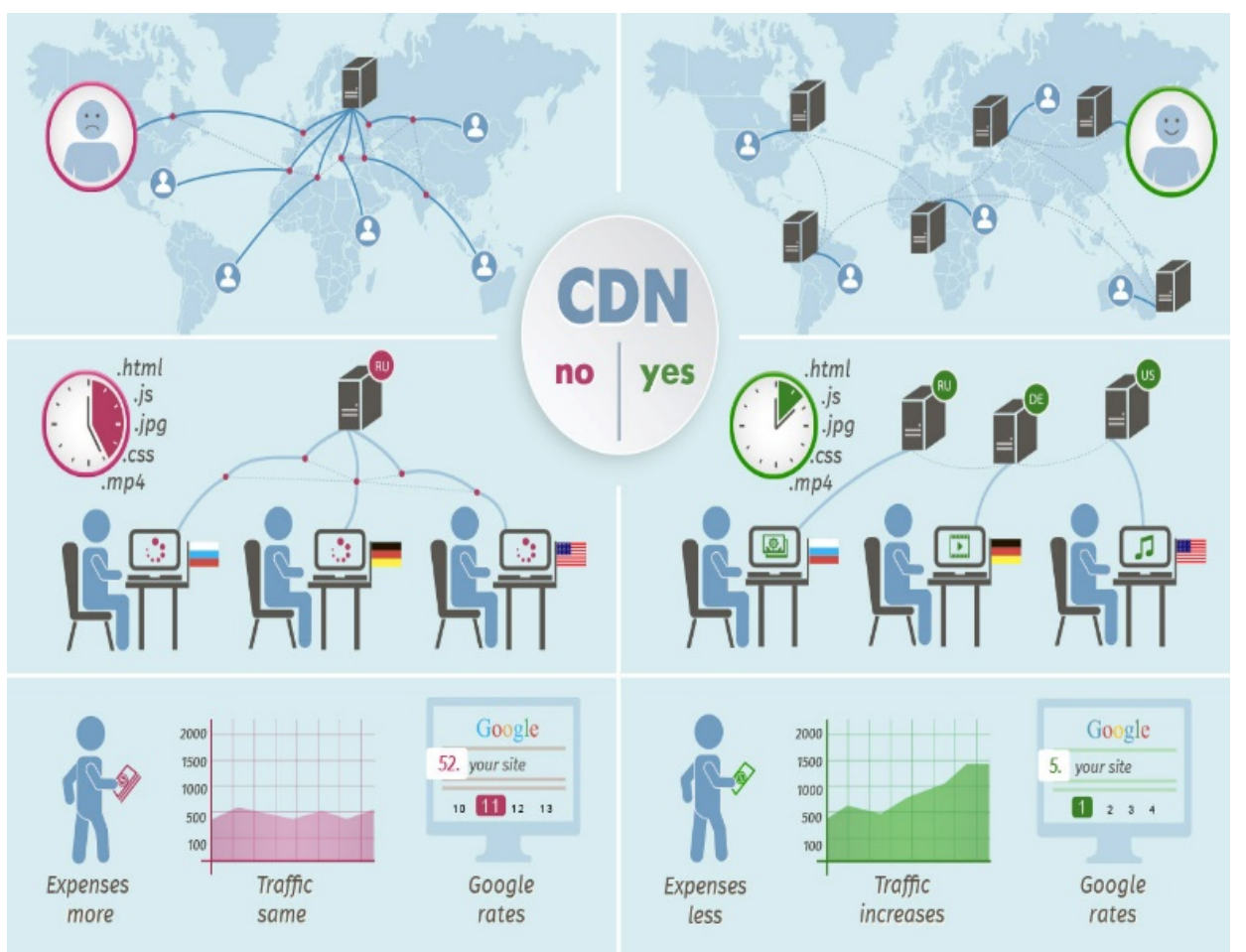

Figure 1. Advantages of CDN [8]

The following are the disadvantages of the CDN service,

- Initial Cost: The benefits of CDN are largely related to the size, structure and function of the business. Small businesses can use CDN to provide shared hosting, which can be cost-effective, but can incur initial costs.

- Location Restrictions: When you use a CDN, your business must host data at a remote location and be aware of whether the content is affected by that data.

- Dynamic Content Security: CDNs are particularly well suited for hosting static content. However, most dynamic content must be stored on the source server. Viruses and attackers can use this dynamic content delivery process to attack CDN.

- Difficult Troubleshooting: When hosting data on many local servers, the overall troubleshooting for the site becomes difficult to change

\section{Online Delivery of Digital Textbooks}

Online delivery means that content is provided over the network. Content providers offer a variety of content over the Internet, and users can download and use the content to their computers and mobile devices. In order to suggest an efficient way for delivering digital textbooks online, we analyze first the current situation. In order to delivery digital contents on-line, it is necessary to consider the characteristics of digital contents as well as the security of the network [9] and network protocol [10] in the wireless connection environment.

\subsection{Contents and Functions of Digital Textbook}

A digital textbook is a new type textbook that extends traditional print matter with a wealth of learning material, such as glossary of used terms, multimedia data, self-assessment questions, supplementary and in-depth content, as well as the tools that help students learn and manage learning material.

The list below outlines the main features of digital textbooks [11-12-20].

- Learning support: Multimedia helps integrate a wide range of content for training needs. It further allows granular customization by accurately selecting reference materials for individual self-paced learning.

- Interactivity: Hyperlinks help interact with a variety of content in real time, and can easily link to additional and reference materials. They can further improve learning effectiveness with interactions, such as click-to-answer confirmation and choosing presentation order.

- Multiplatform support: Support for PCs, smart phones, and other devices allow users to consume the provided content in a convenient way. It is further possible to improve content realism and interactivity using various sensors and input-output features of the end-user device.

- Linked learning: Educational materials can be converged bringing together relevant data across 
different grades of the same curriculum and/or different relevant disciplines [23, 24, 25].

- Two-way learning: Interactions and immediate feedback make it possible to organize student-focused classroom activities and self-paced learning.

- Textbook tools: Compared to print media, digital textbooks offer better experience for handwriting notes, annotations, bookmarks, etc.

- Assessment and learning management: Digital textbooks facilitate self-paced learning and learning management by providing assessment questions, possibilities to check the correct answer, in-depth learning materials, as well as managing educational portfolio and learning progress.

Digital textbooks are designed to provide interactive content to students' using information devices. Content types are shown in Table 1.

Extended content, such as video, animation, images and audio offer realistic information about social phenomena, real-life situations and experience. Students can further check out additional content, hands-on examples, and references. Such linking further enhances education effectiveness and facilitates self-directed study with assessment and educational material management.

Table 1. Digital Textbook Content Types

\begin{tabular}{|c|c|c|}
\hline Category & Subcategory & Subcategory \\
\hline \multirow{3}{*}{ Movie } & Example & \\
\hline & Explanation & \\
\hline & Drama & \\
\hline \multirow{4}{*}{ Image } & \multirow{2}{*}{ Photo } & General \\
\hline & & Panoramic \\
\hline & \multirow{2}{*}{ Illustration } & General \\
\hline & & Panoramic \\
\hline \multirow{4}{*}{ Audio } & \multirow{2}{*}{ Speech } & Short \\
\hline & & Long \\
\hline & \multirow{2}{*}{ Song } & Song \\
\hline & & Instrumental \\
\hline \multirow{2}{*}{ Experiment } & Simple & \\
\hline & Complex & \\
\hline \multirow{3}{*}{ Evaluation } & Multiple Choice & \\
\hline & Short Answer Question & \\
\hline & Essay Question & \\
\hline \multirow{3}{*}{ Animation } & Example & \\
\hline & Explanation & \\
\hline & Drama & \\
\hline \multirow{2}{*}{ Glossary } & Definition & \\
\hline & Supplementary explanation & \\
\hline \multirow{3}{*}{ Function } & Interaction & \\
\hline & Complex & \\
\hline & AR-VR & \\
\hline
\end{tabular}




\subsection{Online Services for Curriculum Books}

Among curriculum books we consider learning e-books and officially adopted digital textbooks for schools distributed online. Elementary and middle school students and teachers can download digital textbooks upon authentication.

Table 2. Online Downloads of E-Textbooks

\begin{tabular}{|c|c|c|c|c|}
\hline \multirow{2}{*}{\multicolumn{2}{|c|}{ Year }} & \multicolumn{2}{|c|}{ \# of User Authentication } & \multirow{2}{*}{$\begin{array}{c}\# \text { of } \\
\text { Download }\end{array}$} \\
\hline & & $\begin{array}{c}1^{\text {st }} \\
\text { Semester }\end{array}$ & $\begin{array}{c}2^{\text {nd }} \\
\text { Semester }\end{array}$ & \\
\hline \multirow{3}{*}{$\mathrm{E}$} & 2014 & $98 \%$ & $26 \%$ & $1,491,775$ \\
\hline & 2015 & $97 \%$ & $33 \%$ & 577,566 \\
\hline & 2016 & $97 \%$ & $15 \%$ & 481,444 \\
\hline \multirow{3}{*}{ M } & 2014 & $97 \%$ & $14 \%$ & 360,483 \\
\hline & 2015 & $95 \%$ & $19 \%$ & 149,343 \\
\hline & 2016 & $94 \%$ & $10 \%$ & 129,378 \\
\hline
\end{tabular}

(E: Elementary School, M: Middle School)

Table 2 below outlines data for e-textbook service usage in 2014-2016 according to KERIS (Korea Education and Research Information Service) [13-21].

As shown in the table, the percentage of authorized users for elementary and middle school students is about $97 \%$ for the first semester and varies 10 to $30 \%$ for the second semester. This suggests that about $20 \%$ of students make repeated downloads in the second semester, whereas total downloads in the first semester are five to ten times more than in the second. Compared to the previous year, the number of downloads goes down (about 60\% in 2015, and about $16 \%$ in 2016). One can also see that elementary school students download e-textbook about 3.8 times more often. KERIS data show that from May 2016 to February 2017 638,000 e-textbooks and 205,000 digital textbooks have been downloaded giving the total of 844,000 items, which amounts to about $70,392 \mathrm{~GB}$ a month. With regard to the item number and subjects of the 2017 downloads, we can see 5 items of English Listening for 3-6 grade elementary school, and 14 items of English e-textbook for 1-3 grade middle school. Digital textbooks on social and scientific subjects were used in pilot research schools: 32 for elementary school and 25 for middle school. The size of listening materials and e-textbooks is about 1.1GB per item; the size of a digital textbook is about 1.3GB per book.

Table 3. 2017 Downloads by Users

\begin{tabular}{|c|c|c|c|}
\hline Kind & $\begin{array}{c}\text { Elementary } \\
\text { (3 6 grade })\end{array}$ & $\begin{array}{c}\text { Middle } \\
(1 \sim 3 \text { grade })\end{array}$ & Total \\
\hline \# of Teachers & $1,785,518$ & $1,457,490$ & $3,243,008$ \\
\hline \# of Students & 183,452 & 109,525 & 292,977 \\
\hline Total & $1,968,970$ & $1,567,015$ & $3,535,985$ \\
\hline
\end{tabular}

In order to estimate the amount and costs of online transmission, we need to know the number of users that is teachers and students and the size of the curriculum. Table 3 shows the number of downloads by elementary and middle school users in 2017 according to KESS (Korean Education Statistics Service) [14-22]. Elementary school (3-6 grade) have 1,968,000 users; middle school (1-3 grade) have 1,567,000 users; of which total teachers are $3,243,000$.

According to "2017 CDN tenancy for online delivery of learning materials" project by KERIS, for the period of 10 months (from 01.05.2017 to 28.02.2018) the budget amounted to 100,098 thousand won (VAT included). The corresponding capacity across the users and subjects required 703,923GB baseline capacity + 140,785GB reserve capacity. The baseline capacity was calculated based on the average capacity per month for the previous year (from May 2016 to February 2017) × 10 months (business period) in consideration of 2017 year plan for digital textbook expansion for up to 5,000 schools. The reserve capacity was assumed $20 \%$.

\subsection{Online Delivery Methods}

Students and teachers are encouraged to search and download e-textbooks and digital textbooks on Edunet [15], an educational Web service operated by KERIS and integrated with $\mathrm{CDN}$ for online delivery.

As shown in Figure 2, the online delivery process contains the following roles: User, Content Provider, Edunet Service, and CDN Service. Users are students and teachers who request learning materials. The Content Provider is a publisher who offers e-textbooks and digital textbooks.

The CDN Service supports online downloads. The Edunet Service provides information about the curriculum, conditions of purchase, and the required viewer. Generally, the online delivery process for a curriculum can be divided into the following steps: registration, purchasing, and download. Step details are given below.

1). Curriculum registration: In this step (1) Content Providers supply curriculum information to the Edunet service, (2) register curriculum with the CDN service. This is a one-off step, provided curriculum information and contents do not change.

2). Curriculum purchase: Within this step (1) users request school administrator to purchase the curriculum, (2) the school administrator registers purchase information with the Edunet service. This step is needed every time purchase information changes.

3). Curriculum download: Within this step (1) users search the curriculum using the Web service, check curriculum information, and proceed to purchase, (2) the Web service checks purchase information on the administrative page, (3) the CDN service prompts the user to download the curriculum, (4) the user downloads the curriculum, (5) when the download is over, the download status is reported to the administrative page. This step is performed every time the user requests curriculum download. 


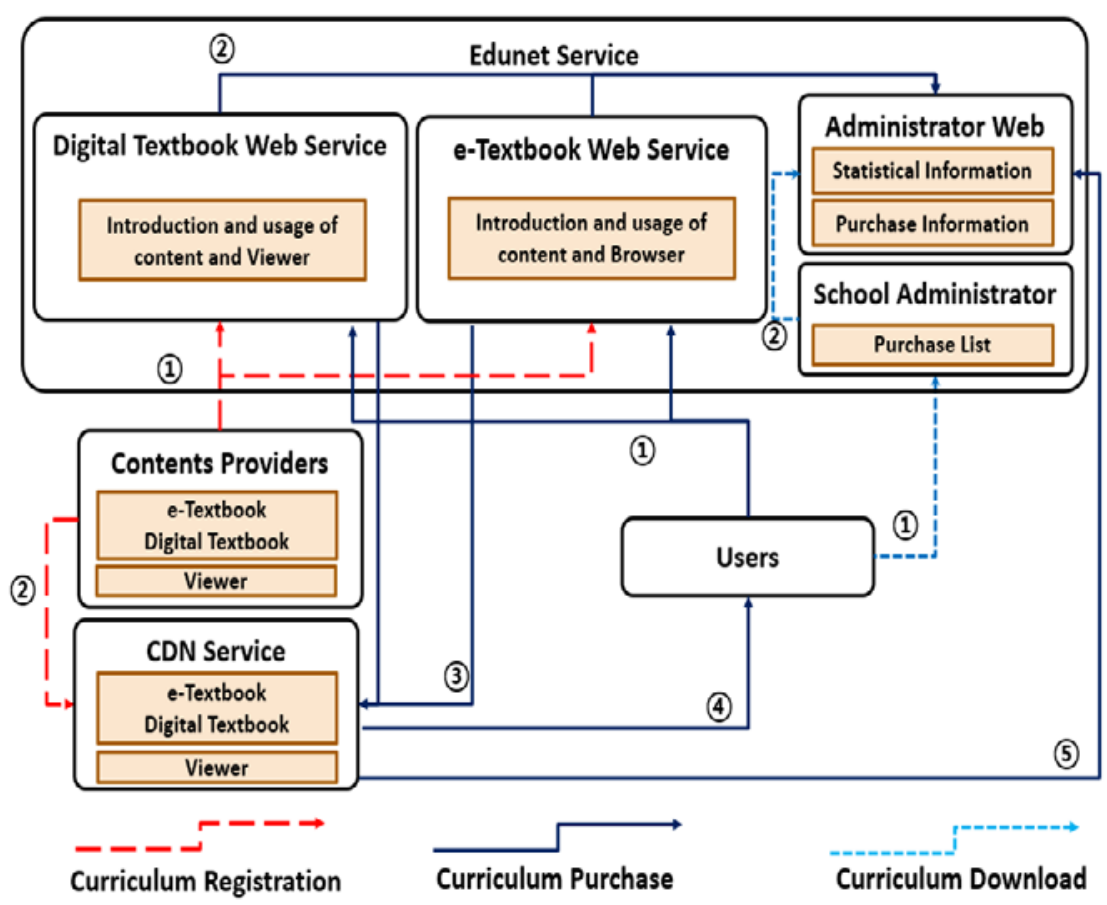

Figure 2. Online Delivery Process

\section{Delivering Digital Textbooks Online}

Online delivery of digital textbooks is much cheaper than offline distribution. It is also more convenient to users as they can use their favorite devices without restriction. The delivery service, however, requires a solid infrastructure for reliable and efficient transfer of large-capacity digital textbooks. Bearing in mind that the service is used for nation-wide delivery, its design and operation will have a great impact on data availability and overall user experience. To this end, we need to consider a number of factors, such as the type and the number of digital textbooks, the number of users and usage scenarios in schools, costs associated with different digital textbook, viewers and selected delivery method.

\subsection{Online Transfer Capacity of Digital Textbooks}

We consider individually the number of students and the number of digital textbooks for elementary, middle and high school by grade for which we calculate the annual delivery amount. As shown in Table 4, as of 2018, there are a total of 76 digital textbooks of which 8 items for elementary school (Society and Science) are approved manuals, and the other 68 items are authorized editions. By school type: 18 items for elementary school, 29 items for middle school, and 29 items high schools. By subject: 17 items are social studies, 6 items are scientific disciplines, and 52 are items English language.
Table 4. Types and Number of Digital Textbooks (as of 2018)

\begin{tabular}{|c|c|c|c|c|}
\hline \multirow{2}{*}{ Kind } & \multicolumn{4}{|c|}{ \# of Digital Textbook } \\
\cline { 2 - 5 } & $\begin{array}{c}\text { Social } \\
\text { Studies }\end{array}$ & Science & English & Total \\
\hline E & 4 & 4 & 10 & 18 \\
\hline M & 14 & 2 & 13 & 29 \\
\hline H & 0 & 0 & 29 & 29 \\
\hline Total & 18 & 6 & 52 & 76 \\
\hline
\end{tabular}

(E: Elementary School, M: Middle School, H: High School)

Table 5. Number of School Students (based on 2018)

\begin{tabular}{|c|c|c|c|c|c|}
\hline \multicolumn{2}{|c|}{ Kind } & \multicolumn{4}{c|}{ \# of Student } \\
\hline & Grade & 2018 & 2019 & 2020 & 2021 \\
\hline \multirow{4}{*}{ E } & 3 & 432,777 & 456,806 & 460,403 & 450,000 \\
\cline { 2 - 6 } & 4 & 451,635 & 432,777 & 456,806 & 460,403 \\
\cline { 2 - 6 } & 5 & 476,043 & 451,635 & 432,777 & 456,806 \\
\cline { 2 - 6 } & 6 & 433,721 & 476,043 & 451,635 & 432,777 \\
\hline \multirow{4}{*}{ M } & 1 & 416,848 & 433,721 & 476,043 & 451,635 \\
\cline { 2 - 6 } & 2 & 450,253 & 416,848 & 433,721 & 476,043 \\
\cline { 2 - 6 } & 3 & 467,187 & 450,253 & 416,848 & 433,721 \\
\hline \multirow{4}{*}{$\mathrm{H}$} & 1 & 457,674 & 467,187 & 450,253 & 416,848 \\
\cline { 2 - 6 } & 2 & 510,241 & 457,674 & 467,187 & 450,253 \\
\cline { 2 - 6 } & 3 & 570,661 & 510,241 & 457,674 & 467,187 \\
\hline \multicolumn{2}{|c|}{ Total } & $4,667,040$ & $4,553,185$ & $4,503,347$ & $4,495,673$ \\
\hline
\end{tabular}

(E: Elementary School, M: Middle School, H: High School) 
Table 5 shows 2018 KESS estimation of the number of students in elementary, middle, and high school by grade for the next following years. The number of students using digital textbooks will slightly go down from $4,667,000$ in 2018 to 4,553,000 in 2019, and about 4.5 million in 2020. This downward trend continues in 2021 resulting in the total number of students of 4,495,000 $(450,000$ in elementary school 3 grade). The number of elementary school teachers in 2018: 186,000 people in elementary school, 109,000 people in middle school, and 134,000 people in high school.

In 2017, the Ministry of Education has introduced wireless access points (up to 4 per school) and smart terminals (max. 60 per school) for 635 small elementary schools in rural and island areas. The adoption of wireless infrastructure in elementary schools is steadily increasing. With the rate of $26.5 \%$ in 2017, it is expected to reach $100 \%$ by 2020 . For middle schools the rate was $20.4 \%$ in 2016, and is expected to reach $100 \%$ in 2021 . If digital textbooks are used only in classrooms, the school wireless infrastructure is affected only to some extent. However, when digital textbooks are further used in home and on end-user devices, the corresponding costs should be considered as well. When students share computers and smart devices at school, however, the number of students has little effect on school wireless infrastructure.

Table 6 shows the number of teachers and students using digital textbooks for the period 2018 to 2020 . Elementary school students include grades 3-6, middle and high school students include grades 1-3; the number of teachers includes all grades.

Figure 3 shows the yearly trends of the number of users which include elementary, middle, and high school students and teachers in Table 6. From 2018 to 2021, the number of users declined slightly for four years, but there is no significant change. The number of elementary school users is about 1.8 million, the number of middle school users is about 1.45 million, and the number of high school users is about 1.5 million.

Table 6. Number of School Students and Teachers (based on 2018)

\begin{tabular}{|c|c|c|c|c|c|}
\hline \multirow{2}{*}{ Kind } & \multicolumn{4}{|c|}{ \# of Student } & \multirow{2}{*}{ \# of Teacher } \\
\hline & 2018 & 2019 & 2020 & 2021 & \\
\hline E & $1,794,176$ & $1,817,261$ & $1,801,621$ & 1,799,985 & 186,684 \\
\hline M & $1,334,288$ & $1,300,822$ & $1,326,612$ & 1,361,399 & 109,906 \\
\hline $\mathrm{H}$ & $1,538,576$ & $1,435,102$ & $1,375,114$ & 1,334,288 & 134,227 \\
\hline Total & $4,667,040$ & $4,553,185$ & $4,503,347$ & $4,495,673$ & 430,817 \\
\hline
\end{tabular}

(E: Elementary School, M: Middle School, H: High School)



Figure 3. Number of School Users per Year 
For elementary school subjects we take science, social studies, and English language. For middle school subjects we take science, and social studies. For high school subjects, we take English language, and English reading and writing.

Table 7 shows estimates of the annual transmission rate assuming that the size of digital textbooks is $0.3 \mathrm{~Gb}$ to 1.0 $\mathrm{Gb}$ and that the number of users and three digital textbooks per user are used.

Table 7. Download Size of Digital Textbook

\begin{tabular}{|c|c|c|c|c|}
\hline \multirow{2}{*}{$\begin{array}{c}\text { Digital } \\
\text { Textbook } \\
\text { Size }\end{array}$} & \multicolumn{4}{|c|}{ Download Size } \\
\cline { 2 - 5 } & 2018 & 2019 & 2020 & 2021 \\
\hline $0.3 \mathrm{~Gb}$ & $4,588 \mathrm{~Tb}$ & $4,485 \mathrm{~Tb}$ & $4,440 \mathrm{~Tb}$ & $4,433 \mathrm{~Tb}$ \\
\hline $0.5 \mathrm{~Gb}$ & $7,646 \mathrm{~Tb}$ & $7,476 \mathrm{~Tb}$ & $7,401 \mathrm{~Tb}$ & $7,389 \mathrm{~Tb}$ \\
\hline $1.0 \mathrm{~Gb}$ & $15,293 \mathrm{~Tb}$ & $14,952 \mathrm{~Tb}$ & $14,802 \mathrm{~Tb}$ & $14,779 \mathrm{~Tb}$ \\
\hline
\end{tabular}

Of course, not all students do use digital textbooks. Also, the size of digital textbooks may vary greatly. On the other hand, users can use more than one device. We also note a spike in the downloads at the beginning of the school semester.

\subsection{Considerations for Online Delivery Service Infrastructure}

Online delivery services need the corresponding supporting infrastructure. Service provisioning differs depending on the constructed network environment, used transport services, leased networking hardware and how the principal operates them. Table 8 outlines some considerations for online delivery service infrastructure construction. From a network perspective, user experience is associated with the website of the online download service, which should support reliable downloads of large digital textbook taking into account the quality of user Internet connection. P2P downloads for user resources should not be allowed. Because user activity greatly increases in the beginning of the semester, it is necessary to provide for variable server load and ensure smooth service even in case of peaks. Distributed network infrastructure is required to ensure response speed and smooth future expansion. The platform should be able to support downloads, caching, streaming, and mobile remoting. In order to speed up large content downloads, chunking support is further necessary. Other mechanisms for improving online transfer rates should be considered as well. (For example, content sharing between caching servers in the network and adjusting optimal transfer rate.)

From security perspective, user authentication and content security should be supported to prevent unauthorized server access and illegal content use. From operational perspective, the system should support 24/7 normal service level and have emergency response facilities ready for nighttime and public holidays. Detailed logging is needed to help resolve service failures and real-time anomalies. Redundant capacity is further required to ensure uninterrupted service. To monitor and assess online delivery status, real-time network traffic statistics (hourly, daily, weekly, monthly, etc.) is needed along with the ability to query for a variety of ongoing information, such as the number of visitors and content views. From management and operations perspective, we should consider the costs of the infrastructure equipment, power usage fees, $\mathrm{H} / \mathrm{W}$ and $\mathrm{S} / \mathrm{W}$ maintenance costs, security and control costs, personnel wages and insurance costs required to operate the service.

Table 8. Online Delivery Service Infrastructure

\begin{tabular}{|c|c|}
\hline Item & Considerations \\
\hline Network & $\begin{array}{l}\text { - Download environment for large-volume } \\
\text { multimedia data } \\
\text { - Network environment for stable and flexible } \\
\text { service } \\
\text { - Network environment for shortening online } \\
\text { transmission time }\end{array}$ \\
\hline Security & $\begin{array}{l}\text { - Security of contents } \\
\text { - Security of network service }\end{array}$ \\
\hline Copyrights & $\begin{array}{l}\text { - Responsibility of digital textbooks and materials } \\
\text { distribution }\end{array}$ \\
\hline $\begin{array}{c}\text { User } \\
\text { Convenience }\end{array}$ & $\begin{array}{l}\text { - Download all contents from one site } \\
\text { - Same usage of all contents with same browser }\end{array}$ \\
\hline $\begin{array}{c}\text { Statistical } \\
\text { Information }\end{array}$ & - Provide various real-time statistical information \\
\hline Cost & $\begin{array}{l}\text { - Network construction and operation cost } \\
\text { - System construction and management cost }\end{array}$ \\
\hline User & $\begin{array}{l}\text { - The number of target students by grade } \\
\text { - Computer environment of student and school } \\
\text { (device, computing power) } \\
\text { - Download period }\end{array}$ \\
\hline Contents & $\begin{array}{l}\text { - Types and size of digital textbooks } \\
\text { - Types and size of digital materials }\end{array}$ \\
\hline
\end{tabular}

\subsection{Digital Textbooks Subjects and Viewers}

Rights and obligations with regard to online delivery of digital textbooks, as well as the associated costs depend on who is the principal. There are two main principals in the process. First, the Ministry of Education who provides integrated management of nationally approved textbooks. There are also independent publishers who develop authorized digital textbooks and manage them on their own. The following considerations apply to integration of online delivery and the viewers.

1) Online transfer costs: Unit cost per GB can reduced by integrating approved and authorized textbooks. Also, if the publisher operates own or leased equipment separately, the overall cost of infrastructure management and operation increases.

2) Online delivery method: Integrated online delivery increases access to digital textbooks as users can receive content in the same way. If download method differs for each content type, this can only inconvenience the users. 
3) Statistics: Collecting statistical information on digital textbook usage is very important for the purpose of analyzing service usability and effectiveness, as well as to improve content and functionality of digital textbooks. Statistical information on digital textbook usage should be managed in a systematic manner.

4) Content authentication: Integrated user authentication and content security can reduce user discomfort and the costs associated with the development of individual certificates and maintaining network security.

5) Viewer: Unified approach further simplifies managing the viewer application. A common viewer would enhance user experience and make it possible to develop consistent add-ons that extend program functionality. Also, this would reduce the costs of program development, distribution, and maintenance.

\subsection{Delivering Digital Textbooks Online}

textbooks involves the following roles: User, Unified Content Provider, CDN Service, Digital Textbook Web Service, and School Administrator. Users are students and teachers. Unified Content Provider refers to content provisioning only, not the publisher who develops digital textbooks.

As shown in Figure 4, while individual publishers provide content, it is the online transfer processor that delivers digital textbooks to content providers. The school administrator manages purchase information for each school, and the Admin Web service handles purchase information and usage statistics for digital textbooks. Digital Textbook Web Service provides information about the content and the viewer of a digital textbook. In this study we propose a unified online transmission service for nationally approved and authorized digital textbooks. Such unified service would facilitate common online delivery of digital textbooks content, data files, and viewers over a CDN.

As shown in Figure 4, online delivery of digital

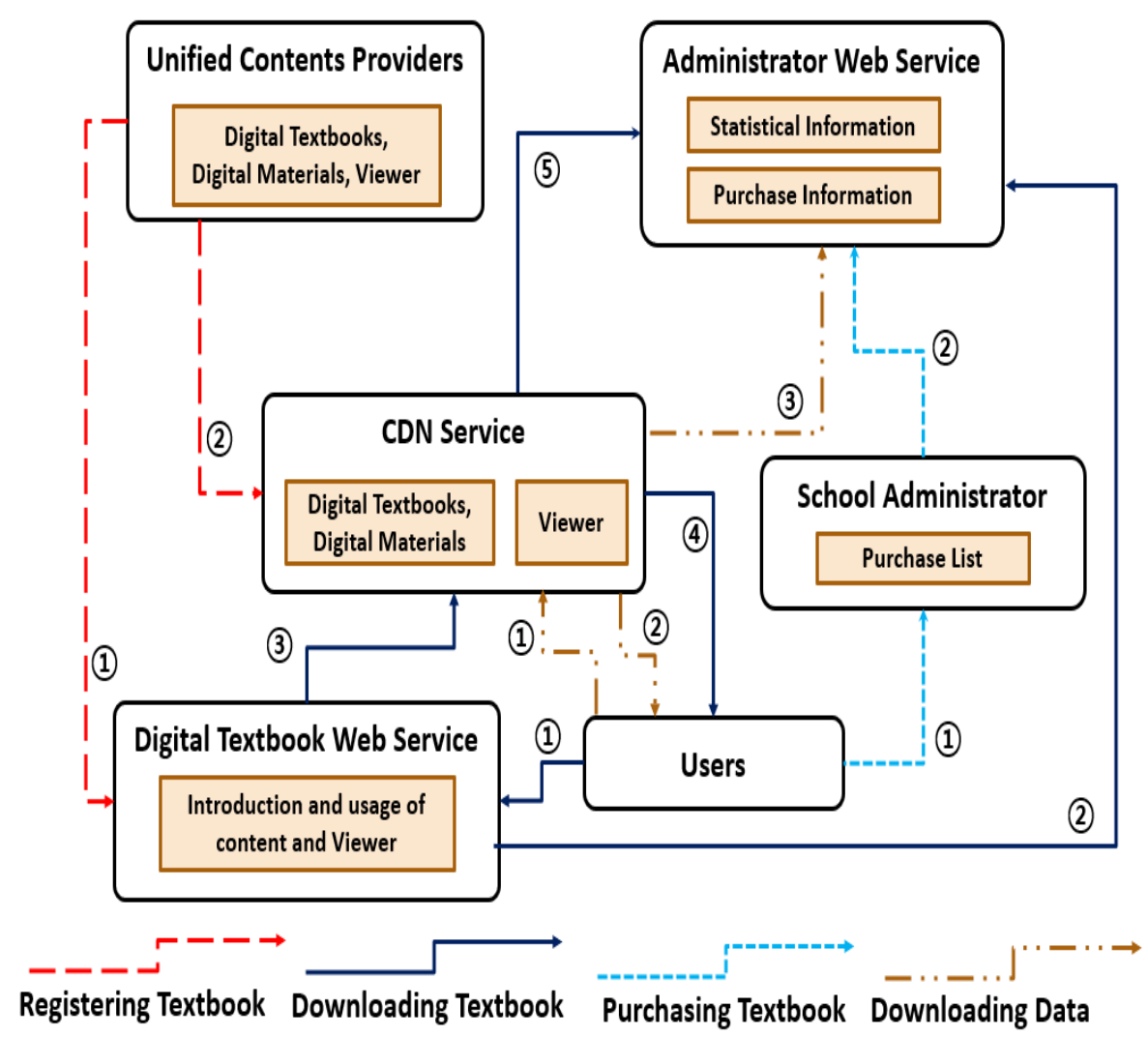

Figure 4. Online Delivery of Digital Textbooks 
The whole process involves the following steps: registration of digital textbook, purchase, download of digital textbook, download of additional data files not included in the textbook.

1) Registration of Digital Textbook: The registration of digital textbook occurs when content provider uploads a new curriculum or modifies the existing digital textbook, the viewer, or the accompanying data. Within this step (1) Provide information about digital textbook, viewer and accompanying data to Digital Textbook Web services, (2) digital textbooks, viewers and accompanying data are registered with the CDN service. This is a one-off step, provided curriculum information, content, and viewers do not change.

2) Digital textbook purchasing: Within this step (1) users request school administrator to purchase the curriculum, (2) the school administrator registers purchase information with the administrative page. This step is needed every time the purchase information changes.

3) Download Digital Textbook: Within this step (1) users search the curriculum using the Web service, check curriculum information, and proceed to purchase, (2) the Web service checks purchase information on the administrative page, (3) the CDN Service prompts the user to download the curriculum, (4) the user downloads the curriculum, (5) upon download completion, the download status is reported to the administrative page. This step occurs when the user moves to downloading digital textbook or the viewer.

4) Data download: Downloading additional data files that are not included in the digital textbook (1) user use the viewer to request downloading materials from the CDN service, (2) CDN service verifies user information, and the user proceeds to data download, (3) when the download is complete, download status is reported to the Administrator. This step is performed every time the user requests downloading accompanying materials not included in the digital textbook itself. In this case, user authentication data are supplied by the viewer without requesting the Administrative Web service.

\section{Conclusions}

Following the convergence of education and ICT, digital textbooks are changing the effectiveness of learning and the methods used. Compared to traditional textbooks, digital textbooks offer efficient means of changing the role of students and teachers in the learning process, help overcome existing shortcomings, and enable tailored training for specific educational levels. In order to enhance the availability and usability of digital textbooks, a robust online delivery service is required In this study we have analyzed the existing digital textbooks and e-textbooks, textbook users, online transmission, costs, and delivery methods for digital textbook pilot projects. Also, in order to propose an online delivery service system, we have examined network environment, security, operations, infrastructure construction, and current status of online transfer of various contents for nationally approved and authorized textbooks. The online delivery service for digital textbooks requires building and operating a reliable and efficient infrastructure for large amounts of data. The selected infrastructure design will greatly affect availability and usability of digital textbooks for end users, as well as influence the development and operation of the online delivery service for both nationally approved and authorized digital textbooks. In this study we suggest a system based on a CDN service and propose a unified online delivery schema for efficient management of digital textbooks and viewers.

A digital textbook itself does not depend on the framework, so it can easily employ all the advanced features. We believe that interactivity and additional content will help support cross-curricular and student-teacher interactive classrooms, as well as greatly facilitate student self-paced learning.

\section{Acknowledgements}

This study was supported by the research fund of the Korea Education and Research Information Service (KERIS) in 2018. The content of this paper is only the opinion of the researchers. It may be different from the official viewpoint of the Korea Education and Research Information Service.

\section{REFERENCES}

[1] S. H. Jang, "Study on Service Models of Digital Textbooks in Cloud Computing Environment for SMART Education," International Journal of $\mathrm{u}$ - and e- Service, Science and Technology, 7(1), pp.73-82, 2014.

[2] Y. J. Joo, S. Y. Park, E. K. Shin, “Students' expectation, satisfaction, and continuance intention to use digital textbooks," Computers in Human Behavior, 69, pp. 83-90, 2017.

[3] M. H. Kim, K. H. Yoo, C. Park, J. S. Yoo, H. S. Byun, W. Y. Cho, J. H. Ryu. N. G. Kim, "An XML-Based Digital Textbook and Its Educational Effectiveness,” LNCS 6059, pp. 509-523, 2010.

[4] B. G. Lee, S. J. Kim, K. C. Park, S. J. Kim, E. S. Jeong, "Empirical Analysis of Learning Effectiveness in u-Learning Environment with Digital Textbook," KSII Transactions on Internet \& Information Systems, 6(3), pp. 869-885, 2012. 
[5] H. A. Tran, S. Hoceini, A. Mellouk, J. Perez, S. Zeadally, "QoE-based server selection for content distribution networks," IEEE Transactions on Computers, 63(11), pp. 2803-2815, 2014.

[6] Remache, A., \& Ibrahim, M. K. Business English Syllabus Design: Putting Students Needs First. International Journal of English Language and Literature Studies, 7(4), pp. 81-93, 2018.

[7] Rotova, N. A. Development of Independence among Future Primary School Teachers by Applying Interactive Learning Methods. Journal of Education and e-Learning Research, 5(2), pp. 118-121, 2018.

[8] Rusok, N. H. M., Kumar, N., \& Ab Rahman, S. M. A Contemporary Approach to Entrepreneurship Education and Training. International Journal of Asian Social Science, 7(8), pp. 696-707, 2017.

[9] Saeed, N., \& Kayani, A. I. Role of College Principals in Promoting Quality of Education in District Kotli AJ\&K. Asian Journal of Contemporary Education, 2(2), pp. 149-158, 2018.

[10] Samaila, M., Uzochukwu, O. C., \& Ishaq, M. Organizational Politics and Workplace Conflict in Selected Tertiary Institutions in Edo State, Nigeria. International Journal of Emerging Trends in Social Sciences, 4(1), pp. 26-41, 2018.

[11] Jermsittiparsert K, Namdech P, Akahat N. Opinions of Voters towards the Issue of Political Participation during the General Election of 2014: The Case of Kalasin, Thailand. Review of European Studies. 2016;8(1):178-84.

[12] Khalid N, Pahi MH, Ahmed U. Losing your best talent: Can leadership retain employees? The dilemma of the banking sector of Hyderabad Sindh, Pakistan: A mediation investigation. International Review of Management and Marketing. 6(3). 2016

[13] Sandy, W. Factors Influencing Indonesian Students Satisfaction during their Studies in China. Asian Journal of Contemporary Education, 2(2), pp. 136-148, 2018.

[14] Shi, W., \& Qu, P. A Comparative Study on Chinese and English Compliments from the Perspective of Intercultural Communication. International Journal of English Language and Literature Studies, 7(4), pp. 133-137, 2018.

[15] Suryanto, T., Haseeb, M., \& Hartani, N. H. The Correlates of Developing Green Supply Chain Management Practices: Firms Level Analysis in Malaysia. International Journal of Supply Chain Management, 7(5), pp. 316. 2018.

[16] H. Yin, X. Zhang, T. Zhan, Y. Zhang, G. Min, \& D. O. Wu, "NetClust: A framework for scalable and pareto-optimal media server placement," IEEE Transactions on Multimedia, 15(8), pp. 2114-2124, 2013.

[17] S. Manfredi, F. Oliviero, S. P. Romano, "Distributed management for load balancing in content delivery networks," In GLOBECOM Workshops (GC Wkshps), 2010 IEEE, pp. 579-583, 2010.

[18] ORPICAL group website, https://orpical.com/should-you-u se-a-content-delivery-network

[19] M.A. Abbas and J.P. Hong, "Survey on Physical Layer Security in Downlink Networks," Journal of Information and Communication Convergence Engineering, 15(1), pp. 14-20, 2017.

[20] H. H. Choi, “Adaptive and Prioritized Random Access and Resource Allocation Schemes for Dynamic TDMA/TDD Protocols", Journal of Information and Communication Convergence Engineering, 15(1), pp. 28-36, 2017.

[21] J. S. Yu, P. Kim, J. H. Na, "Study on Digital Textbook Price System and Online Transmission Method,” KERIS Research Report, 2017.

[22] J. S. Yu, P. Kim, "Study on Certified Digital Textbook Contents,” KERIS Research Report, 2018.

[23] KERIS website, Available: http://www.keris.or.kr

[24] Korean Education Statistics Service website, http://cesi.kedi.re.kr/eng/index

[25] Edunet Service website, http:// http://www.edunet.net 